(c) American Dairy Science Association, 2006.

\title{
Presynchronization with Gonadotropin-Releasing Hormone Does Not Improve Fertility in Holstein Heifers
}

\author{
H. Rivera, R. A. Sterry, and P. M. Fricke ${ }^{1}$ \\ Department of Dairy Science, University of Wisconsin, Madison 53706
}

\begin{abstract}
Holstein dairy heifers were randomly assigned to 1 of 2 treatments to determine whether a presynchronization strategy using GnRH would improve reproductive performance after synchronization of ovulation and timed artificial insemination (TAI). Heifers $(n=82)$ in the first treatment (GPG) received a hormonal protocol for synchronization of ovulation and TAI $(100 \mu \mathrm{g}$ of GnRH, d 0; $25 \mathrm{mg}$ of $\mathrm{PGF}_{2 \alpha}$, d 6; $100 \mu \mathrm{g}$ of GnRH + TAI, $d$ 8); whereas heifers $(n=84)$ in the second treatment (GGPG) received GPG, but with the addition of a $\mathrm{GnRH}$ injection $(100 \mu \mathrm{g}) 7 \mathrm{~d}$ before initiation of the GPG protocol. The proportion of heifers receiving AI before $d 8$ was similar for GPG (4.9\%) and GGPG (9.5\%), and the proportion of heifers diagnosed pregnant $30 \mathrm{~d}$ after AI did not differ between treatments ( 45 vs. $51 \%$, respectively). Treatment did not affect the proportion of heifers ovulating after the second GnRH injection or the proportion in which a corpus luteum regressed after treatment with $\mathrm{PGF}_{2 \alpha}$. In conclusion, presynchronization with $\mathrm{GnRH} 7 \mathrm{~d}$ before initiation of synchronization of ovulation using $\mathrm{GnRH}$ and $\mathrm{PGF}_{2 \alpha}$ did not affect the proportion of heifers expressing estrus before TAI or improve synchronization response or fertility to the synchronization protocol.
\end{abstract}

Key words: presynchronization, gonadotropin-releasing hormone, dairy heifer, timed artificial insemination

\section{INTRODUCTION}

Ovsynch was the first protocol developed to successfully synchronize ovulation and allow for timed artificial insemination (TAI) in lactating dairy cows (Pursley et al., 1995); however, the first studies using Ovsynch and TAI in dairy heifers resulted in a pregnancy rate per artificial insemination (PR/AI) after TAI that was 20 to $40 \%$ less than that of heifers receiving AI to a standing estrus (Pursley et al., 1997). The increased incidence of estrus before TAI in dairy heifers (18 to

Received April 6, 2006.

Accepted May 5, 2006.

${ }^{1}$ Corresponding author: pmfricke@wisc.edu
24\%; Rivera et al., 2004, 2005) may result from an inconsistent response to the first GnRH injection of the protocol (Martinez et al., 2002). Administration of the first GnRH injection between 14 and $18 \mathrm{~d}$ after ovulation coincides with the emergence of a new follicular wave in 3- and 4-wave animals (Ginther et al., 1996) when the dominant follicle from the preceding wave has lost ovulatory capacity and the future dominant follicle from the just-emerged third (Sirois and Fortune, 1988; Ginther et al., 1989; Sartori et al., 2004) or fourth follicular wave (Sirois and Fortune, 1988) has not yet undergone deviation and acquired ovulatory capacity (Sartori et al., 2001). Because of this lack of ovulation to the first $\mathrm{GnRH}$ injection during the latter stages of the estrous cycle, the corpus luteum $(\mathbf{C L})$ originating from the preceding spontaneous ovulation regresses before $\mathrm{PGF}_{2 \alpha}$ treatment and heifers display estrus about $5 \mathrm{~d}$ after administration of the first GnRH injection of the synchronization protocol (Rivera et al., 2004, 2005).

Several strategies have been tested to overcome expression of estrus during protocols for timed $\mathrm{AI}$ in dairy heifers. Inclusion of a controlled internal drug releasing device between the first 2 injections of the protocol successfully suppressed estrus without compromising fertility (Peeler et al., 2004; Rivera et al., 2005); however, the success of this strategy was partially negated by the cost associated with inserting controlled internal drug releasing devices into all heifers receiving the protocol. Presynchronization with 2 injections of $\mathrm{PGF}_{2 \alpha}$ administered $14 \mathrm{~d}$ apart increased fertility in lactating dairy cows receiving Ovsynch (Moreira et al., 2001; Navanukraw et al., 2004). Also, dairy heifers initiating a synchronization of ovulation program during an environment of high progesterone $\left(\mathbf{P}_{\mathbf{4}}\right)$ between $\mathrm{d} 5$ and 10 of the estrous cycle had optimal synchrony and fertility after TAI compared with heifers initiating the protocol during other stages of the cycle (Moreira et al., 2000). Another potential strategy would be to induce an environment of high $\mathrm{P}_{4}$ that can be sustained until $\mathrm{PGF}_{2 \alpha}$ treatment by inducing ovulation of a follicle 6 or $7 \mathrm{~d}$ before onset of a $\mathrm{GnRH}-\mathrm{PGF}_{2 \alpha}-\mathrm{GnRH}$ (GPG) protocol by administering exogenous $\mathrm{GnRH}$ to cause a follicle to ovulate and produce a CL. This strategy may allow for a greater ovulatory response after the first GnRH 
injection of the protocol by synchronizing emergence of a new follicular wave to ensure the presence of a dominant follicle $7 \mathrm{~d}$ later at the first $\mathrm{GnRH}$ injection of the protocol.

The objective of this study was to evaluate the effect of a $\mathrm{GnRH}$ injection administered $7 \mathrm{~d}$ before the onset of a protocol for synchronization of ovulation and TAI in dairy heifers. We hypothesized that treatment with $100 \mu \mathrm{g}$ of GnRH $7 \mathrm{~d}$ before the first injection of the protocol would decrease the proportion of heifers displaying estrus before scheduled TAI by causing a follicle to ovulate and induce a new CL and by synchronizing onset of a new follicular wave. To test this hypothesis, we used a modified Ovsynch protocol evaluated in nonlactating Holstein heifers in 2 previous experiments (Rivera et al., 2004, 2005) in which the interval from the first $\mathrm{GnRH}$ injection to the $\mathrm{PGF}_{2 \alpha}$ injection was 6 rather than $7 \mathrm{~d}$.

\section{MATERIALS AND METHODS}

\section{Facilities and Management of Heifers}

This field trial was conducted on a custom dairy heifer growing company located in south-central Wisconsin comprising approximately 300 breeding-age Holstein heifers originating from 1 dairy operation. Heifers arrived at the facility around $13 \mathrm{mo}$ of age; however, there was considerable variation in age (range 9 to $19 \mathrm{mo}$ ) among heifers enrolled in the experiment. After arrival at the growing facility, heifers were sorted into each of 5 pens according to body size and date of arrival. Heifers had a 1- or 2-wk adaptation period before onset of the AI period. Heifers were fed a TMR based on corn silage, alfalfa haylage, and mineral mix once daily between 0730 and $0900 \mathrm{~h}$ throughout the AI period.

Every 2 to $3 \mathrm{wk}$, a group of 34 to 37 heifers initiated the AI period. The duration of the AI period was set as the time necessary to reach pregnancy, with a maximum time allowed of $120 \mathrm{~d}$. Tail chalk was applied and evaluated daily $(0800 \mathrm{~h})$ during the feeding period after heifers were restrained in self-locking head gates, with the decision to AI based on rubbed tail chalk. Each week the herd veterinarian conducted pregnancy diagnoses via rectal palpation for all heifers in which $35 \mathrm{~d}$ or more had elapsed since their most recent AI. Heifers were returned to the dairy after a confirmed pregnancy and were housed with natural service bulls until moved to a maternity pen before their expected date of parturition.

\section{Treatments}

This experiment was conducted in 5 replicates $(\mathrm{n}=$ approximately 33 heifers/replicate) initiated from April to July 2003. One week before onset of the AI period (e.g., experimental $d-7)$, heifers $(n=166)$ were randomly assigned to receive either synchronization of ovulation using GnRH (Cystorelin; Merial Ltd., Duluth, GA) and $\mathrm{PGF}_{2 \alpha}$ (Lutalyse, Pharmacia Animal Health, Kalamazoo, MI) and TAI (100 $\mu \mathrm{g}$ of $\mathrm{GnRH}, \mathrm{d}$ 0; $25 \mathrm{mg}$ of $\mathrm{PGF}_{2 \alpha}, \mathrm{d} 6 ; 100 \mu \mathrm{g}$ of $\mathrm{GnRH}+\mathrm{TAI}, \mathrm{d}$ 8) followed by $\mathrm{AI}$ after rubbed tail chalk for the remainder of the AI period (GPG; $\mathrm{n}=82$ ), or GPG but with the addition of a GnRH injection administered $7 \mathrm{~d}$ before initiation of the protocol (i.e., $d-7$ ) followed by AI after rubbed tail chalk for the remainder of the AI breeding period (GGPG; $\mathrm{n}=84$ ). Detection of estrus and AI after rubbed tail chalk began on d 0. One professional AI technician with more than $10 \mathrm{yr}$ of experience conducted all inseminations throughout the study, and a maximum of 35 TAI were performed per replicate. Body condition scores were assigned to each heifer at first AI by the same individual throughout the experiment using a quarterpoint scale from 1 to 5 , where $1=$ emaciated and $5=$ obese (Ferguson et al., 1994).

\section{Blood Sampling and Radioimmunoassay}

Blood samples were collected from all heifers via venipuncture of the median caudal vein or artery just before administration of each injection in both treatments, and d -7 for GPG heifers. Blood samples were allowed to clot for $24 \mathrm{~h}$ at $4^{\circ} \mathrm{C}$, were centrifuged $(3,000 \times g$ for $15 \mathrm{~min}$ ), and serum was harvested and stored at $-20^{\circ} \mathrm{C}$ until assayed for $\mathrm{P}_{4}$ using a solid-phase, no-extraction radioimmunoassay (Coat-a-Count Progesterone, Diagnostic Products Corporation, Los Angeles, CA). Serum collected from a diestrus cow was used as a quality control sample within each assay. Intra- and interassay coefficients of variation for the quality control sample were 5.2 and $7.7 \%$, respectively.

Blood sampling and hormone injections for any heifer receiving AI after rubbed tail chalk during the protocol were discontinued after AI. Heifers with a serum $\mathrm{P}_{4}$ concentration $>1.0 \mathrm{ng} / \mathrm{mL}$ just before treatment with $\mathrm{PGF}_{2 \alpha}$ were considered to have a functional CL. Luteal regression occurred when serum $\mathrm{P}_{4}$ concentration decreased to $\leq 1.0 \mathrm{ng} / \mathrm{mL}$ or there was a decrease of $60 \%$ or more of the $\mathrm{P}_{4}$ concentration at treatment with $\mathrm{PGF}_{2 \alpha}$ by $48 \mathrm{~h}$ after treatment (Rivera et al., 2004).

\section{Ultrasonography}

Ovarian structures were monitored using an ultrasound machine equipped with a transrectal 4.5- to 8.5$\mathrm{MHz}$ linear-array transducer (Easi-Scan; BCF Technology Ltd., Livingston, UK). During each ultrasound examination conducted on $d 0,6,8$, and 10 , a sketch of 
the location and diameter of all ovarian structures $\geq 8$ $\mathrm{mm}$ in diameter was recorded. For each ovarian structure, diameter was calculated from a single frozen image of the apparent maximal diameter using on-screen background gridlines resulting in squares with $10-\mathrm{mm}$ sides. Ovulatory response after the GnRH injection on $\mathrm{d} 0$ was determined on $\mathrm{d} 6$ by the presence of a new or accessory CL according to follicular and luteal structures recorded on $\mathrm{d} 0$. Ovulatory response after treatment with GnRH on $\mathrm{d} 8$ was determined by the presence of 1 or more dominant follicles at the time of the GnRH injection and the absence of 1 (single ovulation) or 2 (double ovulation) of those follicles at an ultrasound examination conducted $48 \mathrm{~h}$ later (Fricke et al., 1998). Synchronization rate was defined as the proportion of heifers with serum $\mathrm{P}_{4} \leq 1.0 \mathrm{ng} / \mathrm{mL}$ at the second $\mathrm{GnRH}$ injection and in which ovulation occurred by $48 \mathrm{~h}$ after the second $\mathrm{GnRH}$ injection expressed as a percentage of the total number of heifers receiving the protocol. Pregnancy status was determined $30 \mathrm{~d}$ after first AI by transrectal ultrasonography. Visualization of a fluidfilled uterine horn and the presence of a conceptus were used as positive indicators of pregnancy (Fricke et al., 1998).

\section{Statistical Analyses}

Treatment effects on continuous variables (days to first AI, days to estrus expression, follicle diameter, and serum $\mathrm{P}_{4}$ ) were analyzed using the GLM procedure of SAS (SAS Institute, 1999). Treatment effects on dichotomous outcomes were analyzed using the LOGISTIC procedure of SAS. A multivariate logistical regression model was developed to analyze the effects of the categorical variables treatment, replicate, method of AI (detected estrus vs. TAI), age, age by treatment interaction, and treatment by replicate interaction, with the continuous variable BCS on the combined PR/AI to detected estrus and TAI. A second multivariate logistical regression model was used to analyze the effects of the categorical variables treatment, replicate, ovulatory response to the first GnRH injection, ovulatory response to the second GnRH injection, age, age by treatment interaction, and the treatment by replicate interaction, with the continuous variables BCS and follicular diameter at TAI on PR/AI to TAI. A third multivariate logistical regression model was used to analyze the effects of the categorical variables treatment, replicate, age, age by treatment interaction, and the treatment by replicate interaction, with the continuous variable BCS on the PR/AI to detected estrus.

All multivariate logistical regression models were constructed using a backward selection process with treatment retained as a fixed factor in each of the mod- els. A Wald statistic criterion of $P<0.15$ was set for inclusion of a variable in the model. For analysis of PR/ AI to detected estrus, only treatment remained in the final model. For analysis of PR/AI to TAI, treatment and ovulatory response to the second $\mathrm{GnRH}$ remained as variables in the final model. For analysis of the overall PR/AI, treatment and method of AI remained as variables in the final model. Odds ratios and 95\% confidence intervals were calculated for significant main effects remaining in the final models. Data are presented as percentages and proportions with $P$-values for main effects and interactions derived from the multivariate logistical regression analysis. Treatment differences with $P<0.05$ were considered significant, and differences between $P>0.05$ and $P<0.10$ were considered statistical tendencies.

\section{RESULTS AND DISCUSSION}

\section{Expression of Estrus and Fertility to $\mathrm{Al}$}

Contrary to our hypothesis, the proportion of heifers displaying estrus before scheduled TAI and the mean day of expression of estrus during the protocol did not differ between treatments (Table 1). A previous study reported no difference in expression of estrus when postpartum beef cows were presynchronized with GnRH $7 \mathrm{~d}$ before the onset of a synchronization program using sequential injections of $\mathrm{GnRH}$ followed by $\mathrm{PGF}_{2 \alpha}$ 6 d later (DeJarnette et al., 2001). The overall proportion of heifers displaying estrus during this protocol was less than in previous studies in which $18 \%$ (Rivera et al., 2004) and 24\% (Rivera et al., 2005) of heifers were detected in estrus and inseminated before scheduled TAI. Differences among these studies in the proportion of heifers detected in estrus during a GPG protocol may be due to accuracy of estrus detection based on rubbed tail chalk among heifer operations. In a previous study conducted on a different custom heifer growing operation in Wisconsin, only $8.2 \%$ of heifers inseminated based on rubbed tail chalk had serum $\mathrm{P}_{4} \geq 1 \mathrm{ng} /$ $\mathrm{mL}$ on the day of AI resulting in an overall accuracy of 91.8\% (Rivera et al., 2004). Cordoba and Fricke (2002) reported an $84 \%$ submission rate to first AI during a 23-d AI period using a tail paint system in lactating dairy cows managed in a grazing-based system, whereas a 95\% submission rate after synchronization of estrus was reported by Macmillan et al. (1988) using a similar tail painting system in dairy heifers.

The possible physiological basis for the occurrence of expression of estrus during the GPG protocol in dairy heifers has been described (Rivera et al., 2004, 2005). Variation in the proportion of follicular waves per estrous cycle among individual heifers may explain the low response to presynchronization with $\mathrm{GnRH}$. In one 
Table 1. Expression of estrus behavior and pregnancy rate per artificial insemination (PR/AI) for Holstein dairy heifers submitted to synchronization of ovulation and timed AI (TAI) without (GPG) or with (GGPG) presynchronization with GnRH

\begin{tabular}{lcc}
\hline & \multicolumn{2}{c}{ Treatment $^{1}$} \\
\cline { 2 - 3 } Item & GPG & GGPG \\
\hline Days (mean \pm SEM) from GnRH treatment on d 0 to first AI & $7.8 \pm 0.1$ & $7.6 \pm 0.1$ \\
$\begin{array}{l}\text { Expression of estrus before scheduled TAI, \% } \\
\text { (no./no.) }\end{array}$ & 4.9 & 9.5 \\
Day (mean \pm SEM) of premature expression of estrus & $(4 / 82)$ & $(8 / 84)$ \\
Heifers submitted to TAI, \% & $3.5 \pm 1.2$ & $4.1 \pm 0.6$ \\
(no./no.) & 95 & 90 \\
PR/AI to estrus, 30 d after AI, \% & $(78 / 82)$ & $(76 / 84)$ \\
(no./no.) & 75 & 75 \\
PR/AI to TAI, 30 d after AI, \% & $(3 / 4)$ & $(6 / 8)$ \\
(no./no.) & 44 & 49 \\
Overall PR/AI 30 d after AI, \% & $(34 / 78)$ & $(37 / 76)$ \\
(no./no.) & 45 & 51 \\
Twin fetuses, 30 d after AI, \% & $(37 / 82)$ & $(43 / 84)$ \\
(no./no.) & 0 & 2.3 \\
\end{tabular}

${ }^{1} \mathrm{GPG}$ heifers received synchronization of ovulation and TAI ( $100 \mu \mathrm{g}$ of GnRH, d 0; $25 \mathrm{mg}$ of PGF $\mathrm{P}_{2}, \mathrm{~d} 6$; $100 \mu \mathrm{g}$ of GnRH + TAI, d 8), whereas GGPG heifers received GPG but with the addition of a GnRH injection $(100 \mu \mathrm{g}) 7 \mathrm{~d}$ before $(\mathrm{d}-7)$ initiation of the GPG protocol. No effect of treatment was detected for any end point.

report, the proportion of heifers exhibiting 2,3 , and 4 waves of follicular growth was 20,70 , and $10 \%$, respectively (Sirois and Fortune, 1988). In a study comparing nonlactating heifers with lactating cows, the proportion of animals with 2,3 , and 4 follicular waves was 55.6, 33.3 , and $11.1 \%$, respectively, for heifers, and 78.6, 14.3, and $7.1 \%$, respectively, for lactating cows. Thus, differences in follicular wave dynamics between nonlactating heifers and lactating cows may explain differences in responsiveness to Ovsynch. Due to the high variation in patterns of follicular growth among dairy heifers, the proximity to proestrus at the onset of synchronization treatment has a detrimental effect on the synchronization of follicular wave emergence. The greater proportion of heifers with 3 and 4 follicular waves per cycle results in a more rapid follicular turnover than that observed in 2 -wave heifers. For heifers with 4 waves, wave turnover is around $6.3 \mathrm{~d}$ compared with a $7.8 \pm$ $0.6 \mathrm{~d}$ interval from emergence of the last wave to ovulation in 3-wave heifers (Sartori et al., 2004). As a consequence, heifers with 4 follicular waves may not ovulate a follicle to 2 sequential GnRH injections when the interval between injections is $7 \mathrm{~d}$.

Fertility at $30 \mathrm{~d}$ after AI was similar between treatments $[P=0.54$; adjusted odds ratio $=0.82 ; 95 \%$ confidence interval $=0.44$ to 1.53 ; Table 1]. Overall, PR/ AI was similar to previous reports from dairy heifers receiving AI after standing estrus of $47 \%$ (Donovan et al., 2003), 59\% (Gwazdauskas et al., 1981), and 55 to $66 \%$ (Butler and Smith, 1989). Although there was a tendency $(P=0.07$; adjusted odds ratio $=3.40 ; 95 \%$ confidence interval $=0.88$ to 13.10 ) for an effect of TAI vs. AI to rubbed tail chalk on PR/AI (Table 1), the number of heifers receiving AI after rubbed tail chalk was too few $(n=8)$ to make a statistically valid conclusion. The professional AI technician in the present study had an average PR/AI of 42 to $53 \%$ on this same heifer operation during the 12 mo preceding initiation of this experiment. No multiple ovulations or twin fetuses were detected for GPG heifers, whereas 4.5\% (3/66) of GGPG heifers had double ovulations and 2.3\% (1/43) had twin fetuses (Tables 1 and 2). No effect of BCS on reproductive performance was detected. Several heifers $(5 \% ; 4 / 80)$ diagnosed pregnant to the first AI service on d 30 received an intervening AI service based on rubbed tail chalk after the first service, but before pregnancy diagnosis.

\section{Synchronization Response}

Based on the total number of heifers assigned to each treatment on d 0 , synchronization rate was similar between treatments (Table 2). Our results were similar to those of DeJarnette et al. (2001), who reported no difference in synchronization response after presynchronizing beef cows with GnRH with a similar presynchronization protocol. No benefit of presynchronization was found on estrus response, synchronization rate, PR/AI, or synchronized PR/AI (Johnson et al., 2000) when beef cows were pretreated with $\mathrm{GnRH} 7 \mathrm{~d}$ before initiation of a $\mathrm{GnRH}-\mathrm{PGF}_{2 \alpha}$ protocol followed by AI after standing estrus. Ovulation rate after the second GnRH injection was similar to previous studies, in which Ovsynch was evaluated in lactating dairy cows 
Table 2. Ovarian responses and synchronization rate of Holstein dairy heifers submitted to synchronization of ovulation and timed artificial insemination (TAI) without (GPG) or with (GGPG) presynchronization with $\mathrm{GnRH}$

\begin{tabular}{lcc}
\hline & \multicolumn{2}{c}{ Treatment $^{1}$} \\
\cline { 2 - 3 } Item & GPG & GGPG \\
\hline $\mathrm{n}$ & 82 & 84 \\
Diameter (mean \pm SEM) of ovulatory follicle at & & $11.5 \pm 0.5$ \\
GnRH administration on d 0, mm & $11.8 \pm 0.5$ & 39 \\
$\begin{array}{l}\text { Ovulation after GnRH administered on d 0, } \% \\
\text { (no./no.) }\end{array}$ & 40 & $(31 / 80)$ \\
Luteal regression, ${ }^{2} \%$ & 94 & 89 \\
(no./no.) & $(64 / 68)$ & $(58 / 65)$ \\
Diameter of ovulatory follicle at second GnRH, mm (mean \pm SEM) & $11.9 \pm 0.2$ & $12.1 \pm 0.2$ \\
Ovulation after GnRH administered on d 8, \% & 85 & 87 \\
(no./no.) & $(66 / 78)$ & $(66 / 76)$ \\
Double ovulation after GnRH administered on d 8, \% & 0 & 4.5 \\
(no./no.) & $(0 / 66)$ & $(3 / 66)$ \\
Synchronization rate, ${ }^{3} \%$ & 69 & 64 \\
(no./no.) & $(57 / 82)$ & $(54 / 84)$ \\
Synchronized PR/AI, ${ }^{4} \%$ & 49 & 57 \\
(no./no.) & $(28 / 57)$ & $(31 / 54)$ \\
\hline
\end{tabular}

${ }^{1} \mathrm{GPG}$ heifers received synchronization of ovulation and TAI $\left(100 \mu \mathrm{g}\right.$ of $\mathrm{GnRH}, \mathrm{d}$ 0; $25 \mathrm{mg}$ of $\mathrm{PGF}_{2 \alpha}, \mathrm{d}$ 6; $100 \mu \mathrm{g}$ of GnRH + TAI, d 8), whereas GGPG heifers received GPG but with the addition of a GnRH injection $(100 \mu \mathrm{g}) 7 \mathrm{~d}$ before $(\mathrm{d}-7)$ initiation of the GPG protocol. No effect of treatment was detected for any end point.

${ }^{2}$ Proportion of heifers in which a functional corpus luteum regressed after treatment with $\mathrm{PGF}_{2 \alpha}$ on $\mathrm{d} 6$.

${ }^{3}$ Number of heifers in which functional corpora lutea regressed after treatment with $\mathrm{PGF}_{2 \alpha}$, on d 6 and in which a follicle ovulated within $48 \mathrm{~h}$ after treatment with $\mathrm{GnRH}$ on $\mathrm{d}$ 8, expressed as a percentage of heifers receiving the hormonal protocol.

${ }^{4}$ Number of heifers diagnosed pregnant expressed as a percentage of synchronized heifers.

(Fricke et al., 1998; Vasconcelos et al., 1999). In the present study, synchronized PR/AI did not differ between treatments (Table 2). By contrast, DeJarnette et al. (2001) reported a tendency for an increased synchronized PR/AI in beef cows presynchronized with GnRH $7 \mathrm{~d}$ before initiation of the protocol. Adjusting the total PR/AI of $48 \%$ (80/166) observed in the present study to include only the 132 heifers that ovulated after the second GnRH injection would increase PR/AI to $61 \%$ (80/132). Thus, this modified PR/AI may reflect the expected PR/AI for the heifers that synchronized follicular and luteal function and had an opportunity to conceive. Overall, incidence of double ovulation in the present study $(2.3 \%$; 3/132) was consistent with previous reports in dairy heifers (Ryan and Boland, 1991; Rivera et al., 2004, 2005).

The proportion of heifers with functional CL on d 6 and regression of functional CL after treatment with $\mathrm{PGF}_{2 \alpha}$ (determined by high $\mathrm{P}_{4}$ on $\mathrm{d} 6$ and low $\mathrm{P}_{4}$ on $\mathrm{d}$ 8 ), was similar between treatments. The proportion of heifers with functional CL on d 6 and proportion of functional CL that regressed after treatment with $\mathrm{PGF}_{2 \alpha}$, defined as high $\mathrm{P}_{4}$ on $\mathrm{d} 6$ and low $\mathrm{P}_{4}$ on $\mathrm{d} 8$, were similar between treatments (Table 2). These data are consistent with other reports in dairy heifers after synchronization of ovulation using Ovsynch (Pursley et al., 1997) or the same GPG protocol tested in the present experiment (Rivera et al., 2004).

Follicular diameter at treatment with $\mathrm{GnRH}$ on d 8 affected $(P<0.01)$ ovulatory response to that injection independent of treatment $(12.0 \pm 0.2$ vs. $9.9 \pm 0.7 \mathrm{~mm}$ for ovulatory vs. nonovulatory follicles, respectively). This agrees with the report that follicles in lactating dairy cows did not acquire ovulatory capacity until they underwent deviation and reached a minimum diameter of $10.0 \mathrm{~mm}$ (Sartori et al., 2001). Ovulatory response to first $\mathrm{GnRH}$ injection affected $(P<0.05)$ ovulatory response to second GnRH injection in GGPG, but not in GPG heifers. For the GPG treatment, 87\% of heifers that ovulated after the first $\mathrm{GnRH}$ ovulated after the second GnRH injection, whereas 97\% of GGPG heifers that ovulated after the first $\mathrm{GnRH}$ injection ovulated after the second injection (data not shown). Despite this observation, a high proportion of heifers failed to ovulate after the first GnRH injection, but ovulated after the second GnRH injection. This observation could be related to the variability in follicular growth patterns observed for dairy heifers reported in other studies (Sirois and Fortune, 1988; Ginther et al., 1989; Sartori et al., 2004). Thus, the low ovulatory response to the GnRH injection administered on d 0 (Table 2) may be related to the high proportion of heifers exhibiting folli- 
Table 3. Effect of treatment on number of corpora lutea $(\mathrm{CL})$ and serum progesterone $\left(\mathrm{P}_{4}\right)$ concentration for heifers receiving timed AI

\begin{tabular}{|c|c|c|c|}
\hline \multirow[b]{2}{*}{ Item } & \multicolumn{2}{|c|}{ Treatment $^{1}$} & \multirow[b]{2}{*}{$P$-value } \\
\hline & GPG & GGPG & \\
\hline $\mathrm{n}$ & 78 & 76 & \\
\hline Heifers with multiple CL on d $0, \%$ & 5 & 32 & \\
\hline (no./no.) & $(4 / 78)$ & $(24 / 76)$ & $<0.01$ \\
\hline Number of CL on d $0($ mean \pm SEM $)$ & $1.0 \pm 0.0$ & $1.3 \pm 0.1$ & $<0.01$ \\
\hline Proportion of pregnant heifers with multiple CL, \% & 3 & 43 & \\
\hline (no./no.) & $(1 / 34)$ & $(16 / 37)$ & $<0.01$ \\
\hline \multicolumn{4}{|l|}{ Mean $( \pm \mathrm{SEM})$ serum $\mathrm{P}_{4}$ concentration $(\mathrm{ng} / \mathrm{mL})$ at: } \\
\hline Treatment with GnRH on d 0 & $2.6 \pm 0.3$ & $3.2 \pm 0.3$ & 0.17 \\
\hline Treatment with $\mathrm{PGF}_{2 \alpha}$ on d 6 & $3.8 \pm 0.3$ & $3.6 \pm 0.3$ & 0.64 \\
\hline Treatment with $\mathrm{GnRH}$ on $\mathrm{d} 8$ & $0.5 \pm 0.1$ & $0.6 \pm 0.1$ & 0.34 \\
\hline
\end{tabular}

${ }^{1} \mathrm{GPG}$ heifers received synchronization of ovulation and TAI (100 $\mu \mathrm{g}$ of $\mathrm{GnRH}, \mathrm{d} 0 ; 25 \mathrm{mg}$ of PGF $\mathrm{PG}_{2 \alpha} \mathrm{d} 6$; $100 \mu \mathrm{g}$ of GnRH + TAI, d 8), whereas GGPG heifers received GPG but with the addition of a GnRH injection $(100 \mu \mathrm{g}) 7 \mathrm{~d}$ before $(\mathrm{d}-7)$ initiation of the GPG protocol.

cles that had not yet acquired ovulatory capacity. Heifers in which follicles did not ovulate after the first or second GnRH injection might reflect a population of heifers with more rapid follicular turnover, such as 4wave heifers. A shorter interwave interval in 4 follicular wave heifers compared with a $7.8 \pm 0.6 \mathrm{~d}$ interval in 3 -wave heifers (Sartori et al., 2004) could account for this response.

\section{Effect of Treatment on Serum $\mathrm{P}_{4}$ Concentration and CL Number}

Heifers were classified as having $(>1)$ or not having (0 or 1 ) multiple CL at the GnRH injection administered on d 0 of the synchronization protocol (Table 3). Although ultrasound evaluation was not conducted on $d$ -7 , the number of heifers with multiple CL as detected by ultrasonography on $d 0$ was greater $(P<0.01)$ for GGPG than for GPG heifers and the mean number of CL was greater $(P<0.01)$ for GGPG than for GPG heifers (Table 3). Mean number of CL at the first GnRH injection is a method for assessing ovulatory response to the presynchronizing injection of GnRH administered on $\mathrm{d}-7$. This assumption, however, is not conclusive because some heifers having only $1 \mathrm{CL}$ present on $\mathrm{d} 0$ could have ovulated after presynchronization treatment, but were in proestrus on $d-7$, in which case the preceding CL most likely regressed by $d 0$. The occurrence of spontaneous or induced double ovulation may confound this end point. Nevertheless, this observation suggests that the failure of GGPG to synchronize the emergence of a new follicular wave on $d-7$ might not be related to a lower ovulatory response than previously reported for dairy heifers (Pursley et al., 1997), but suggests a high variation of follicular growth patterns, as evidenced by the similar ovulatory response after first GnRH injection of the protocol between treatments.

Surprisingly, serum $\mathrm{P}_{4}$ concentration did not differ between treatments on $\mathrm{d} 0,6$, and 8 (Table 3). Mean number of CL detected on d 0 was $0.9 \pm 0.0$ and $2.0 \pm$ $0.0(P<0.01)$ for heifers with multiple $(\mathrm{n}=28)$ and without multiple $(n=28) \mathrm{CL}$, respectively. There was an effect of multiple CL on serum $\mathrm{P}_{4}$ concentration (2.7 \pm 0.2 vs. $3.9 \pm 0.6 \mathrm{ng} / \mathrm{mL}$ for heifers without vs. with multiple CL respectively; $P<0.05$ ) at the onset of synchronization (d 0), and $48 \mathrm{~h}$ after $\mathrm{PGF}_{2 \alpha}$ treatment (d $8 ; 0.5 \pm 0.0$ vs. $0.8 \pm 0.2 \mathrm{ng} / \mathrm{mL}$ for heifers without vs. with multiple CL, respectively; $P<0.05$ ). Heifers with multiple CL had greater $(P<0.05)$ serum $\mathrm{P}_{4}$ concentration at the onset of synchronization (d 0), and at $48 \mathrm{~h}$ after $\mathrm{PGF}_{2 \alpha}$ treatment (d 8), but there was no difference in $\mathrm{P}_{4}$ on d $6(3.8 \pm 0.5$ vs. $3.7 \pm 0.2 \mathrm{ng} / \mathrm{mL}$, respectively; $P>0.10)$.

\section{CONCLUSIONS}

Presynchronization with an injection of $\mathrm{GnRH} 7 \mathrm{~d}$ before the onset of a GPG protocol failed to improve synchronization response in randomly cycling dairy heifers. This is likely due to variation in follicular dynamics among individual dairy heifers. New alternatives for TAI programs in dairy heifers need to be developed or modified to develop TAI protocols that eliminate estrous detection.

\section{ACKNOWLEDGMENTS}

We thank Pharmacia Animal Health (Kalamazoo, MI) for providing Lutalyse and Merial Ltd. (Duluth, GA) for providing Cystorelin for this experiment. This research was supported by Hatch project WIS04431 to PMF. 


\section{REFERENCES}

Butler, W. R., and R. D. Smith. 1989. Interrelationships between energy balance and postpartum reproductive function in dairy cattle. J. Dairy Sci. 72:767-783.

Cordoba, M. C., and P. M. Fricke. 2002. Initiation of the breeding season in a grazing-based dairy by synchronization of ovulation. J. Dairy Sci. 85:1752-1763.

DeJarnette, J. M., M. L. Day, R. B. House, R. A. Wallace, and C. E. Marshall. 2001. Effect of GnRH pretreatment on reproductive performance of postpartum suckled beef cows following synchronization of estrus using $\mathrm{GnRH}$ and $\mathrm{PGF}_{2 \alpha}$. J. Anim. Sci. 79:1675-1682.

Donovan, G. A., F. L. Bennett, and S. P. Frederick. 2003. Factor associated with first service conception rates in artificially inseminated nulliparous Holstein heifers. Theriogenology 60:67-75.

Ferguson, J. D., D. T. Galligan, and N. Thomsen. 1994. Principal descriptors of body condition score in Holstein cows. J. Dairy Sci. 77:2695-2703.

Fricke, P. M., J. N. Guenther, and M. C. Wiltbank. 1998. Effect of decreasing the dose of GnRH used in a protocol for synchronization of ovulation and timed $\mathrm{AI}$ in lactating dairy cows. Theriogenology 50:1275-1284.

Ginther, O. J., L. Knopf, and J. P. Kastelic. 1989. Temporal associations among ovarian events in cattle during oestrous cycles with two and three follicular waves. J. Reprod. Fertil. 87:223-230.

Ginther, O. J., M. C. Wiltbank, P. M. Fricke, J. R. Gibbons, and K. Kot. 1996. Minireview: Selection of the dominant follicle in cattle. Biol. Reprod. 55:1187-1194.

Gwazdauskas, F. C., J. A. Lineweaver, and W. E. Vinson. 1981. Rates of conception by artificial insemination in dairy cattle. J. Dairy Sci. 64:358-362.

Johnson, S. K., D. E. Grum, and M. L. Day. 2000. Addition of GnRH or an intravaginal insert to a GnRH-PGF synchronization system to enhance response to timed breeding in postpartum beef cows. J. Anim. Sci. 78(Suppl. 1):218. (Abstr.)

Macmillan, K. L., V. K. Taufa, D. R. Barnes, A. M. Day, and R. Henry. 1988. Detecting estrus in synchronized heifers using tail paint and an aerosol raddle. Theriogenology 30:1099-1114.

Martinez, M. F., J. P. Kastelic, G. P. Adams, B. Cook, W. O. Olson, and R. J. Mapletoft. 2002. The use of progestins in regimens for fixed-time artificial insemination in beef cattle. Theriogenology 57:1049-1059.

Moreira, F., R. L. de la Sota, T. Diaz, and W. W. Thatcher. 2000. Effect of day of estrous cycle at the initiation of a timed artificial insemination protocol on reproductive responses in dairy heifers. J. Anim. Sci. 78:1568-1576.

Moreira, F., C. Orlandi, C. A. Risco, R. Mattos, F. Lopes, and W. W. Thatcher. 2001. Effects of presynchronization and bovine somatotropin on pregnancy rates to a timed artificial insemination protocol in lactating dairy cows. J. Dairy Sci. 84:1646-1659.

Navanukraw, C., L. P. Reynolds, J. D. Kirsch, A. T. Grazul-Bilska, D. A. Redmer, and P. M. Fricke. 2004. A modified presynchronization protocol improves fertility to timed artificial insemination in lactating dairy cows. J. Dairy Sci. 87:1551-1557.

Peeler, I. D., R. L. Nebel, R. E. Pearson, W. S. Swecker, and A. Garcia. 2004. Pregnancy rates after timed AI of heifers following removal of intravaginal progesterone inserts. J. Dairy Sci. 87:2868-2873.

Pursley, J. R., M. O. Mee, and M. C. Wiltbank. 1995. Synchronization of ovulation in dairy cows using $\mathrm{PGF}_{2 \alpha}$ and $\mathrm{GnRH}$. Theriogenology 44:915-923.

Pursley, J. R., M. C. Wiltbank, J. S. Stevenson, J. S. Ottobre, H. A. Garverick, and L. L. Anderson. 1997. Pregnancy rates per artificial insemination for cows and heifers inseminated at a synchronized ovulation or synchronized estrus. J. Dairy Sci. 80:295-300.

Rivera, H., H. Lopez, and P. M. Fricke. 2004. Fertility of Holstein dairy heifers after synchronization of ovulation and timed AI or AI after removed tail chalk. J. Dairy Sci. 87:2051-2061.

Rivera, H., H. Lopez, and P. M. Fricke. 2005. Use of intravaginal progesterone-releasing inserts in a synchronization protocol before timed $\mathrm{AI}$ and for synchronizing return to estrus in Holstein heifers. J. Dairy Sci. 88:957-968.

Ryan, D. P., and P. M. Boland. 1991. Frequency of twin births among Holstein-Friesian cows in warm dry climate. Theriogenology 36:1-10.

Sartori, R., P. M. Fricke, C. P. Ferreira, O. J. Ginther, and M. C. Wiltbank. 2001. Follicular deviation and acquisition of ovulatory capacity in bovine follicles. Biol. Reprod. 65:1403-1409.

Sartori, R., J. M. Haughian, R. D. Shaver, G. J. M. Rosa, and M. C. Wiltbank. 2004. Comparison of ovarian function and circulating steroids in estrous cycles of Holstein heifers and lactating cows. J. Dairy Sci. 87:905-920.

SAS Institute. 1999. SAS/STAT User's Guide. Version 8.2. SAS Institute, Inc., Cary, NC.

Sirois, J., and J. E. Fortune. 1988. Ovarian follicular dynamics during the estrous cycle in heifers monitored by real-time ultrasonography. Biol. Reprod. 39:308-317.

Vasconcelos, J. L. M., R. W. Silcox, G. J. M. Rosa, J. R. Pursley, and M. C. Wiltbank. 1999. Synchronization rate, size of ovulatory the follicle, and pregnancy rate after synchronization of ovulation beginning on different days of the estrous cycle in lactating dairy cows. Theriogenology 52:1067-1078. 